\title{
Culture, Illness and Health Seeking in Rural Setting: A Case in a Village of Comilla, Bangladesh
}

\author{
Md Abdur Rahman ${ }^{1}$, Rabeya Khatun ${ }^{1}$, Md Asaduzzaman ${ }^{1}$ and Asif Ekbal Arif ${ }^{2}$ \\ ${ }^{1}$ Department of Anthropology, Comilla University, Bangladesh \\ ${ }^{2}$ Department of Anthropology, Jatiya Kabi Kazi Nazrul Islam University, Trisal, Mymensingh, Bangladesh
}

*Corresponding author: Asif Ekbal Arif, Assistant Professor, Department of Anthropology, Jatiya Kabi Kazi Nazrul Islam University, Trisal, Mymensingh, Bangladesh

\begin{abstract}
This paper has been explored on the locale's interpretation of illness and remedies in the context of rural setting in Bangladesh. Taking ethnomedical approach as key theoretical lens of medical anthropology within the discipline of cultural anthropology, this study has tried to explore how the local people perceived illness through their experiential and traditional knowledge system and how they managed remedies or health seeking by employing symbolic (knowledge, beliefs etc), structural (family, kinship, social network, social institutional support etc), and material aspects of culture including economic resources. For gathering firsthand data through field experiences, this study has been conducted among the villagers of a village of Comilla District in Bangladesh. However, the data were collected by employing the qualitative tools and techniques of data collection including Key Informant Interview, Focused Group Discussion, Informal Interview and observation. The respondents were selected on the basis of purpossive sampling method. Finally, the data were analyzed in qualitative nature including narrative analysis, content analysis etc.
\end{abstract}

Keywords: Culture, Illness, Health-Seeking, Ethnomedicare

\section{Introduction}

It was a sunny morning in the year of 2014 when we set our journey for the village Belnura (pseudonym) of Comilla District in Bangladesh. Before our expedition to that village, we had informed by some people that was full of mystery and rumors. The rumors were spread out about the death of Mizan, a sixteen-year-old boy of that referred village. The biomedical explanation of his death was that he had problem in backbone. But most of the people in village Belnura believed that his death was beyond such kind of objective explanation of biomedical science. Their interpretation on the cause of his death was something caused by supernatural forces (evil spirit, Gods punishment etc). According to the villager's interpretation that boy died because of hitting a cat by a stick under the banyan tree. Those group of people believed that the cat that was hit by that boy was not a simple cat rather it might be the spirit of ghost or God. However, the debate between the biomedical and supernatural explanation of the cause of the death of that boy granulated our thought into research and for field-based evidence, we went to that village for writing a paper on people's perceptions on illness and remedies. We got interested not only for Mizan's case but we the people of Bangladesh are still getting evidence in the perspective of rural Bangladesh many causes of death and illness remained unknown about the causes of death and illness in the age of modern biomedical science. We collected data not only for the issues of the death of that boy but also we collected some other interpretations of various types of illness and the ways of remedies as well where people interprets their cultural ways of identification of illness and their ways of health seeking which are mediated and constrained by their cultural knowledge [1-3].

However, with our short journey from Comilla, we reached at the village Belnura. Comilla is near about $88 \mathrm{~km}$ distance from the capital city (Dhaka) of Bangladesh and the village Belnura is situated at Lalmai hill area which is only about $10 \mathrm{~km}$ far from Comilla. This village is comprised of small hills where one hundred and thirty families are living. We got information from the perspective of ethnic and religious background of the villagers, most of they are dominant Bengali Muslims and the rests were Tripura ethnic community who were religiously the followers of their forefather's religion and some Tripuras were the followers of Christian religion. This village can be characterized as the lower level of development in terms of modern technological interventions. So these villagers 
have to face various problems in case of communication with cities because of the lower level of roads and transportations. We also noticed that there is no modern health care system for the villagers. Although they are backward in case of modern biomedical health care, they are familiar with some name of modern biomedicine such as saline and pharmaceutical tablets which are available in the village groceries. They are tightly integrated with alternative healing including Ayerbeda, Unani and Homeopathy besides the market dominated biomedicine. However, we came into a consensus with such evidence that this village can be characterized under the pluralistic medical system [4-8].

The occupational diversity of the villagers was notably interested where most of the villagers are engaged in agriculture; some people operate their livelihood on working as day labor, bamboo and wood collector, mason and pulling van and rickshaw. In some other household members are migrant who are working in different part around the globe but most of them are in Middle East. We have already gratified that we would conduct a qualitative study on the referred topic by employing anthropological tools and techniques of collecting, gathering, recording and interpreting qualitative data.

People of every culture have their own generating knowledge on identification of the causation of illness and culturally recognized healing system. The concept of culture is not segregated from their health concern and practices where they live because they cannot separate their health, illness and health seeking from what the beliefs and practices they have. If the concept of culture involves the learned patterns of behavior, it will be definitely interpreting that it is fundamental to consider culture as the main operating engine in case of identification and remedies of illness in a particular culture. As Winkelman (2009) states, "culture defines the kinds of health problems that exist and the resources for responding to health concerns defining our perceptions and producing the resources for responding to them" (Winkelman: 2009:03). Culture is then preferably essential for creating cognitive categories for naming, classifying, ordering and explaining illness and performing the approaches of healing (Winkelman: 2009). The popularity of cultural healing or traditional healing practices has not been declined in the heyday of modernization of health care system in different parts of the world and such kind of practices are evidential in case of Bangladesh. People from all social category usually are seen to visit such cultural sources of healing in Bangladeshi society especially in rural areas. These are considered to be the remnants of the pre-scientific era and looked down upon by the rationalists and the medical fraternity. It is only in recent times that there has been a resurgence of interest in our own heritages as many scientific studies have attempted to unravel how traditional healing system works $[9,10]$.

It has already been mentioned that the notion of health, illness and healing is tightly determined and constrained by culture of the locales where they live. The present study on how people define and identify illness and their ways of remedies through cultural knowledge and resources is based on such cultural models of illness and healing in rural Bangladesh.

\section{Theoretical and Conceptual Framework of this Study}

This study has been approached to the theoretical lens of medical anthropology. Ethnomedical or cultural approach of health and illness has been employed as key theoretical outbreak for exploring people's knowledge on health and illness and their cultural ways and resources of health seeking in village Belnura. Arthur Kleinman's popular of 'explanatory model' has also been employed for understanding illness and remedies from native's point of view. The explanatory model makes a bridge between the cultural domain and the domain of health, disease and illness. Disease thus is not an entity but an explanatory model [11]. disease in this perspective belongs to culture in particular to "to the specialized culture of medicine and culture is not only a means of representing disease but is essentially to its very constitution as a human reality" [11]. The concept of disease and illness need to be discussed because these stands central to the present study. Disease is something what an organ has and illness is something what human has. illness is therefore a subjective response to an individual, and those around him, to being his/her ill; particularly how he/she and they interpret the origin and significance of this event; how its affect behavior, and relationship with other people; various steps taken for remedy to this situation [12]. Lay theories of illness are also part of wider concepts about the origin of misfortune in general. they are based on beliefs about the structure and function of body and the ways in which it can malfunction. Lay theories in general place the aetiology or causation of ill health in the following for layers including withing the individual, in the natural world, in the social world and the supernatural world. in many cases, illness is ascribed to combinations of two or more causes or to interactions between these worlds [12]. The concept of 'medical pluralism' has been employed in case of understanding the health seeking behavior of the villagers.

\section{Methodology of this Study}

It has been referred to earlier that this is a qualitative study where we have employed anthropological tools and techniques of data collection. Fifty-five respondents of three categories; twenty five female, twenty five male and five healers were chosen for collecting first hand data and the respondents were from different socio-economic groups. We employed several techniques for collecting data including key informant interview (KII), informal interview, focused group discussion a (FGD) and case study method. Field notes and diary were taken for recording data. We have collected data from only the Muslims and they were Bangles by ethnically.

\section{Findings and Analysis}

People of Belnura define the event of illness based on their belief system. Young has classified belief systems about ill-health as either externalizing or internalizing. Externalizing belief systems 
concentrate mainly on the aetiology of the illness, which is believed to arise outside the sick person's body, especially in their social world. Thus, our attempt to identify a cause for the individual illness has some reality of such kind of beliefs. Through a discussion with the people of Belnura, we came to know that the native people are infected with cough, fever, diarrhea, high pressure, allergy, diabetes, jaundice and so on. But the most concerning thing is that they suffer from different types of pain- such as chest ache, liver ache, headache, and etc. Different types of pain are very common illness in village. The villagers think it to be the result of over laboring. The male villagers who collect wood and bamboo and work hard usually fall victim to different types of physical pain. In our research, we noticed that even the women who run household chore suffer from physical pain. The villagers also think that Alga (supernatural force or ghosts) are also responsible for illness. Some people again think that supernatural elements also cause of illness.

Table 1.

\begin{tabular}{|c|c|}
\hline Aiya tree & Herbal plant \\
\hline Alga & Supernatural force or Ghost \\
\hline Alga Batash & Supernatural wind \\
\hline Basak Pata & A type of green Herbal leaf \\
\hline Bori & Herbal tablet \\
\hline Devta & God \\
\hline Doa & Buslessing religious specialist \\
\hline Hujur & Terminalia Arjun \\
\hline Hupara tree & Traditional healer \\
\hline Kobiraj & Herbal tree \\
\hline Neem & Herbal Climber \\
\hline Panipora & Charmed water given by religious healers \\
\hline Rivuji lota & Emulate \\
\hline Rona tree & Basil plant \\
\hline Tabij & Abroma augusta \\
\hline Tulsi pata & Plant which produce medicinal savor \\
\hline Udal tree & As produce herbal oil \\
\hline Ulod komol tree & \\
\hline
\end{tabular}

The villagers of Belnura think that illness covers multiple Lucie of interpretations where some interpretations are natural that has logic in natural world and some others are supernatural that logic are beyond natural world. The following case study summarizes people's thoughts and identification of illness in village Belnura.

\section{The Story of Rashi: The Long Expedition of the Identification of Infertility}

Rashi is a 29 years old woman who was married with a 40 years old man in the same village. After the 9 years of their conjugal life, her husband divorced Rashi because her failure to give birth child. Rashi was narrating her experiences by saying that her mother-inlaw made jadu (magic) by the help of sorcery in the nearest village. Rashi told that she tried her best to get a baby and she frequently visited folk healer, sacred place such as mazar, dorga (sacred place) and even in sometimes in modern biomedical health care centers.
Rashi at the end consoled herself by saying that her becoming childless might be a cause of her obesity that was assumed by one of her neighbor.

From the above story of Rashi's diagnosis of infertility in the village Belnura, we have noticed both the 'naturalistic and personalistic' explanation of infertility as illness. Such evidence is also remark where Foster and Anderson have proposed an alternative way of classifying lay illness aetiologies, especially in non-western societies [12]. As referred to earlier in Mizan's case that rural people usually perceive illness such as fever, cough diarrhea and infliction of ghost and the influence of supernatural elements. At the same time we have also got evidence the influences of natural and supernatural forces in case of infertility.

When people perceive that they are ill, they act on this perception and seek medical care. Sociologists call this actions illness behavior. The primary components of illness behavior include acceptance of the sick role and therapeutic interventions [7]. Studies of illness behavior center on patterns of seeking health care; these patterns are called a hierarchy of resort. Another case is provided below in this perspective what have already stated;

\section{The Story of Shamima: The Cultural ways of Diagnosis and Healing of Diarrhea}

Shamima is a 21 years young married woman whose husband worked as a day labor. Her 3 years old child was suffering in patla paikhan (diarrhea). At the first day of the illness of her child, she thought that her child was caught by the alga batash (bad air ) or someone gave by eye while she was feeding and then she decided to visit a huzur (religious folk healer) and took healing. At the second day, she noticed that her child's health condition was becoming more vulnerable than the day before. Showing such signs, she realized that the illness might be serious and it was beyond the previous predictions what she assumed. Taking a quick decision, she visited to a biomedical center and took remedies suggested by one of her educated neighbors in the same village. After a few days, she thought that she would take some future initiatives for her child for the protection of evil spirit zin (such as ghost). Then she visited a kabiraj (folk healer) and took a (tabij) amulet for her child [1317].

If household remedies do not work, the patient and his or her family move up the hierarchy of resort to a health care specialist. Depending on the society, the second step may be to go to biomedical doctor or to a folk healer. If the patient is not cured on this level, and financial resources permit, the patients will seek care from a different, often more specialized, medical practitioner.

Most of the people of the village think that Allah (the Islamic religious ideology that Allah is their creator) has created this world and man is his creature. As Allah creates them, so Allah controls them. That is man's cure is on the will of Allah. So, at the very first, they pray to Allah for cure, next they approach to doctor (biomedical knowledgeable trainer) or folk healer (Kobiraj). The inhabitants of the village usually do not go to doctor without any major issue. 
Village doctor at the corner of the village is their sole-savior. But if it is a major illness, they take the patient Comilla Medical College Hospital or different hospitals of Comilla town. Even, sometimes they approach to Dhaka for treatment. They take treatment from both Huzur and Kobiraj. We came to know about this factor in case study one. So, we can see that there was a pluralistic medical system in Belnura village.

The treatment system of Belnura village largely depends on the pharmacies of village market. From the research, we saw from the research that the villagers take medicine without suggestion of doctor or at the suggestion of compounder when they get attacked with illness to get rid of illness. For this reason, many of them know the name of medicine. For example, when any one in a family catches cold and gets headache, Histacin tablet is served, cinaron for urination, bargon for vomit, imotil for diarrhea. Again, when the degree of diarrhea is much, both imotil and flaggil and for heartache Amaxycillin are served. We are seeing that the rural people know different types of alopatheic medicine and try to get them cured when they feel ill [17-26].

Kobiraji treatment enjoys much popularity in village. If there is no doctor in Belnura village the villagers go to the Kobiraj of other village. And the Kobirajes after the treatment of headache, liver ache; epilepsy and they give divine water, tabiz, pill and special oil as medicine. Besides this, the people of Belnura village take shelter in religious healing when they get ill. Those who are Muslims think that they can get cured by recitation of verses of the holy Quran. For example, people think that after saying prayer, they can get cured of any eye problem by whiffing from the recitation of the Holy Quran. Imam and Huzur of village mosque offer Pani Pora (Charming water), Tabij (amulet) containing holy word to make the village people get rid of disease.

In the field observation, we noticed that they are medicinal plant in the village. The villagers are familiar with these trees in a regular line of descent and they make treatment for themselves. They think the trees to be so effective and they function as a good remedy for getting rid of diseases. Further, they tell us that when they get failed from getting rid of illness, they adopt the medicinal trees and got effective measures. A list is given below regarding the elements like Olod Komol, Rivuji Lota, Hupara tree and Rona tree the village people use to make treatment in their daily life [28-30].

The Olod Komol tree is a medicinal tree to the villagers. This green color tree is seen in most of the houses around the house. From a very regular line of succession, they are using this for the remedy of pain in stomach. If any member of a family gets struck by pain in stomach, he/she is served a glass of water which is prepared from the tip of tree and it is given at afternoon or at evening. This five piece of tips are kept in a glass with water and in the morning, the elements in the glass get very dense but dense not like ice. And they believe that this type of dense water factors in removing pain in stomach. It is also used in the manner to make treatment for headache.

Most of the villagers lead their life by doing agricultural activities. And during this physical labor, often they cut off different organs of their body unintentionally. Consequently, there is bleeding. The villagers use a natural medicine for this bleeding, which is found in near house, near road and in jungle. This is Rivuji Lota. When any one cuts off his/her limb unconsciously, he/she is treated with this Rivuji Lota. At first, the leaves are to be separated from the creeper. Later, the leaves are to be pressed with the palm of the hand and then some juice come out and then the juice is given in the bleeding place. This causes for stopping the bleeding. And this is also helpful for the pain of stomach. For this purpose, at first, it is needed to make the pill with the leaves and then it needs to be kept in the sun to get them dry.

If anyone gets of burn, there is a medicine tree in the village which is named as 'Hupara Tree'. To use this, the skin of the tree at first need to cut off and this needs to be made of seven pieces. Then, the pieces are to be sewed like Kantha sewing. Later, the binding piece needs to be placed in the sorting places. This must be used until the patient gets cured.

If dog bites the villagers, they use this Rona tree. They do not go to any doctor instead use only this treatment. If anyone in the village is bitten by dog, he/she is served the skin of the Rona tree after seven days of the incident. But there are some specific rules in using the juice of the skin of the tree. For example, at first the juice needs to be found out and after seven days not more or less, this juice needs to be drunk in an empty stomach in early in the morning. This cannot be done for more than one time, only one glass to be drunk only for one time. Akkas of fifty years of this village thinks that the usefulness of this juice is that it destroys the influence of poison of dog's bite [31].

Besides this, Aiya tree is locally well familiar which is used for semen problem. The villagers also use the leaves of Basok tree to get rid of cough. The villagers also use the root of shimul tree as medicine. The villagers again use the leaves of Udal tree to get cured from lung problems. The villagers think that the juice of udal tree helps cure lung problem. People use boil water of Nimpata for itches problem. Panic grass is used for sore or bleeding. The outer rind of Arjun tree, the villagers think to be effective for blood pressure and cardio logical problem. Besides these medicinal trees, the villagers use their individual treatment system. For example, they use potato if there is any sore in any limb. Again they use salt mixed water for burned place so that there occurs no blister.

However, the villagers do their own treatment by using the elements that are available to them and through the knowledge they get from their regular succession and through the knowledge of modern medicine which are reflected in their culture and what are closely related to their life $[32,33]$.

Medical systems can be seen as sociocultural systems. There are particular social roles for practitioners and patients; there is a hierarchy of power and prestige among practitioners [7]. We will examine cultural influences on cognition, affect, psychopsychological processes, behavior, and social role, and we will study the psychocultural mechanisms that mediate influences (Kleinman: 1988:119). Through this experiment, we attempted to know the thought of the villagers about illness and the process they 
adopt to get rid of the illness. We noticed that the rural people in a very regular term fall victim to illness. Sometimes they express, sometimes they do not. We noticed also that when anyone gets ill, he or she or his or her relatives attempts to find out any social reason for that illness. These reasons show that people become ill because of natural or supernatural factors. We noticed that the villagers are aware of the natural or supernatural factors which make their relative ill. And for that reason, the members of family try their best to make the members avoid the illness. Again, they pray to Allah so that any supernatural power cannot do any harm to their family members. In our Research, we saw that after doing all these, even if anyone gets ill, they use different medicine system such as Alopathey, homiopathey, Kobiraji, Medicinal, Religious healing as soon as possible and attempt to make early cured. So, we see, there is a pluralistic medical system in Belnura village. In this experiment, we found that the village people make their treatment by their heir knowledge and again they use general elements which are available to them and seeing their medicine practice system, we can learn about their culture. The healing knowledge of the village people hold are closely related to their culture. It is mixed with their everyday life style and custom. So, we can say that this healing knowledge of the rural people helps us understand the culture of this region and if this healing knowledge is not added to health and medicine planning or it is not emphasized then it is impossible to make an acceptable health and medicine planning. Because the negative people cannot accept the matter what is out of their own culture.

\section{References}

1. Ackernecht EH (1971) Medicine and Ethnology: Selected Essays. The Johns Hopkins Press, Baltimore, USA.

2. Alland A Jr (1966) Medical anthropology and bio-cultural adaptation. American Anthropologist 68: 40-57.

3. Alland A Jr (1970) Adaptation in Cultural Evolution: An Approach to Medical Anthropology, Columbia University Press, New York, USA

4. Atran Scott (1999) Managing the Maya commons: The value of local knowledge. Pp. 190-214. In: Ethno-ecology: Situated knowledge / located lives. VD Nazarea (Ed.) University of Arizona Press, Tucson, USA

5. Atte $O$ (1992) Indigenous Local Knowledge as a Key to Local Level Development: Possibilities, constraints, and Planning Issues. Iowa State University, Ames, USA.

6. Barrow EGC (1992) Building on local knowledge: The challenge of agroforestry for pastoral areas. Agro-forestry Today 3(4): 4-7.

7. Brown J Peter (Ed) (1998) Understanding \& Applying Medical Anthropology. Mayfield Publishing Company, California, USA.

8. Barth Fredrik (1990) The guru and the conjurer: Transactions in knowledge and the shaping of the culture in Southeast Asia and Melanesia. Man 25(4): 640-653.

9. Barth Fredrik (2002) An Anthropology of Knowledge. Current Anthropology 43(1): 1-18.

10. Bhasin, Veena and Srivastava VK (1991) Medical anthropology: A review. Journal of Human Ecology 2(1): 1-19.

11. Kleinman A (1973) Medicine’s Symbolic Reality: On the Central Problem in the Philosophy of Medicine. Inquiry 16: 206-613.
12. Helman GC (1994) Culture, Health and Illness, An Introduction for Health Professionals. Butterworth.

13. Ellen RF, Harris H Indigenous Environmental Knowledge in Scientific and Developmental Literature: A Critical Nassessment. University of Kent at Canterbury, Canterbury, UK.

14. Eliade Mircea (1974) Shamanism: Archaic techniques of ecstasy. Bollingen Series LXXVI, Princeton University Press, Princeton, New Jersey, USA.

15. Fabrega Jr H (1972) Medical anthropology. In: Biennial Review of Anthropology. BJ Siegel (Eds.). Stanford University Press, Stanford, USA, pp. 167-229.

16. Fairhead J Rajasekaran, Warren Indigenous Technical Knowledge and Natural Resources Management in Sub-Saharan Africa: A Critical Overview. Natural Resources Institute, Chatham Maritime, Kent, UK.

17. Freed A, Ruth S Freed (1979) Spirit possession as illness in a north Indian village. In: Issues in Cultural Anthropology. David W Mc Curdy \& James P Spradley (Eds.). Waveland Press, USA, pp. 351-371.

18. Good BJ (1977) The heart of what's the matter: The semantics of illness in Iran. Cultural, Medical and Psychiatry 1: 25-58.

19. Harper Edward B (1957) Shamanism in South India. South Western Journal of Anthropology XII: 267-287.

20. Illich Ivan (1974) The medical nemesis. The Lancet 2: 918-921.

21. Jilek WG (1971) From crazy witch doctor to auxiliary psychotherapist: The changing image of the medicine man. Psychiatrica Clinica 4: 200220 .

22. Khare RS (1963) Folk medicine in a north Indian village. Human Organization 22(1): 36-40.

23. Kleinman A (1980) Patients and Healers in the Context of Culture: An Exploration of the Borderland between Anthropology, Medicine and Psychiatry. University of California Press, Berkley, USA.

24. Latour Bruno (1987) Science in Action. Harvard University Press, USA

25. Opler ME (1958) Spirit possession in a rural area of Northern India. In: Reader in Comparative Religion. WA Lessa \& EZ Vogt (Eds.) Evanston, USA, pp. 553-566.

26. Rahmann Rudolf (1959) Shamanistic and Related phenomena in Northern and Middle India. Anthropos LIV: 681-760.

27. Rajpramukh KE (1976) A note on the Shaman among the Jatapus'. Folklore 17(2): 379-381.

28. Rajpramukh KE (2005) The Shaman in Asia Pacific Region: A Cross Cultural Study. Man in India 85(1 \& 2): 25-40.

29. Schafer J (1989) Utilizing indigenous agricultural knowledge in the planning of agricultural research projects designed to aid small scale farmers. In: Indigenous Knowledge Systems: Implications for Agriculture and International Development. DM Warren, LJ Slikkerveer, and SO Tittlola (Eds.). Iowa State University, Ames, USA.

30. Sillitoe Paul (1986) The development of indigenous knowledge. Current Anthropology 39(2): 223-253.

31. Seymour-Smith Charlotte (1986) Macmillan Dictionary of Anthropology. The Charlotte Macmillan Press Ltd, London, UK.

32. Varela F, J Thompson, E Rosch (1991) The Embodied Mind: Cognitive Science and Human Experience. MIT Press Cambridge, UK.

33. Young Allan (1982) The Anthropology of illness and sickness. Annual Review of Anthropology 11: 257-285. 
CC (P) This work is licensed under Creative

To Submit Your Article Click Here: Submit Article

DOI: $10.32474 / J A A S .2019 .01 .000110$

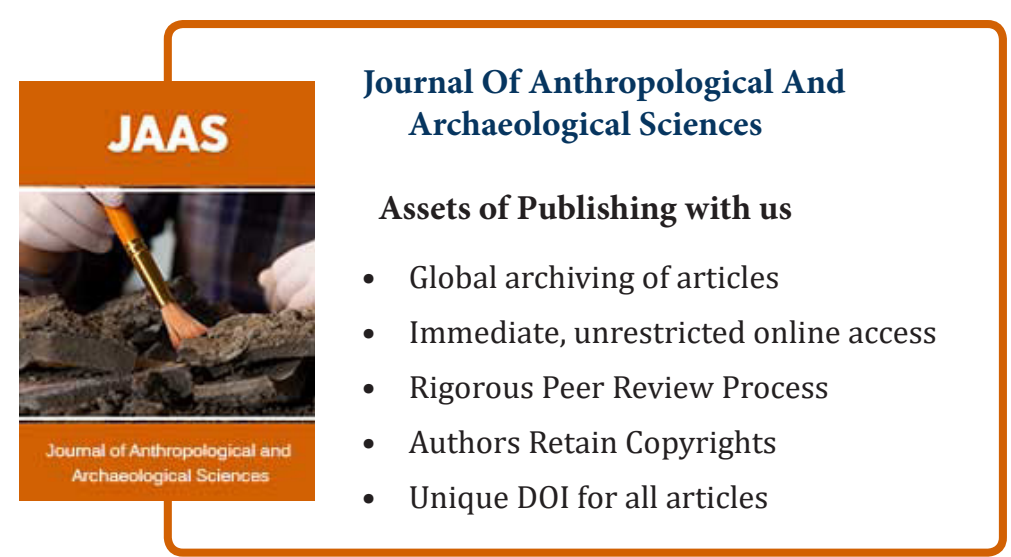

